\title{
Measuring The Concentration of Serum Syndecan-1 To Assess Vascular Endothelial Glycocalyx Injury During Hemodialysis
}

\section{Keigo Kusuzawa}

Gifu University Graduate School of Medicine

\section{Keiko Suzuki}

Gifu University Graduate School of Medicine

Hideshi Okada ( $\sim$ hideshi@gifu-u.ac.jp )

Gifu University Graduate School of Medicine

Kodai Suzuki

Gifu University Graduate School of Medicine

\section{Chihiro Takada}

Gifu University Graduate School of Medicine

\section{Soichiro Nagaya}

Gifu University Graduate School of Medicine

\section{Ryu Yasuda}

Gifu University Graduate School of Medicine Haruka Okamoto

Gifu University Graduate School of Medicine

Takuma Ishihara

Gifu University Hospital

Hiroyuki Tomita

Gifu University Graduate School of Medicine

\section{Yuki Kawasaki}

Gifu University Graduate School of Medicine

\section{Toru Minamiyama}

Gifu University Graduate School of Medicine

\section{Ayane Nishio}

Gifu University Graduate School of Medicine

\section{Hirotsugu Fukuda}

Gifu University Graduate School of Medicine

\section{Takuto Shimada}

Gifu University Graduate School of Medicine

\section{Yuto Tamaoki}


Gifu University Graduate School of Medicine

\section{Tomoki Yoshida}

Gifu University Graduate School of Medicine

\section{Yusuke Nakashima}

Gifu University Graduate School of Medicine

\section{Genki Yoshimura}

Gifu University Graduate School of Medicine

\section{Ryo Kamidani}

Gifu University Graduate School of Medicine

\section{Tomotaka Miura}

Gifu University Graduate School of Medicine

\section{Hideaki Oiwa}

Gifu University Graduate School of Medicine

\section{Fuminori Yamaji}

Gifu University Graduate School of Medicine

\section{Yosuke Mizuno}

Gifu University Graduate School of Medicine

\section{Takahito Miyake}

Gifu University Graduate School of Medicine

\section{Yuichiro Kitagawa}

Gifu University Graduate School of Medicine

\section{Tetsuya Fukuta}

Gifu University Graduate School of Medicine

\section{Tomoaki Doi}

Gifu University Graduate School of Medicine

Akio Suzuki

Gifu University Hospital

\section{Takahiro Yoshida}

Gifu University Graduate School of Medicine

\section{Nobuyuki Tetsuka}

Gifu University Graduate School of Medicine

\section{Shozo Yoshida}

Gifu University Graduate School of Medicine

\section{Shinji Ogura}

Gifu University Graduate School of Medicine

\section{Research Article}

Keywords: Hemodialysis, Glycocalyx, Syndecan-1, Body fluid removal, Nafamostat mesylate 
Posted Date: September 2nd, 2021

DOl: https://doi.org/10.21203/rs.3.rs-846591/v1

License: (9) This work is licensed under a Creative Commons Attribution 4.0 International License. Read Full License

Version of Record: A version of this preprint was published at Frontiers in Medicine on December 23rd, 2021. See the published version at https://doi.org/10.3389/fmed.2021.791309. 


\section{Abstract}

Glycocalyx is present on the surface of healthy endothelium, and the concentration of serum syndecan-1 can serve as an injury marker. This study aimed to evaluate the hemodialysis-associated changes in the serum syndecan-1 concentration. This was a single-center, retrospective, observational study. Between March 2017 and December 2019, 145 patients who underwent hemodialysis at the Gifu University Hospital were enrolled. The median dialysis period and dialysis time were 63 months and 3.7 hours, respectively. The serum syndecan-1 concentration increased from $124.6 \pm 107.8 \mathrm{ng} / \mathrm{mL}$ before hemodialysis to $229.0 \pm 138.1 \mathrm{ng} / \mathrm{mL}$ after hemolysis $(P<0.001)$. Treatment with anticoagulant nafamostat mesylate inhibited hemodialysis-induced increase in the levels of serum syndecan- 1 in comparison to unfractionated heparin. Dialysis time and the change in concentration of syndecan- 1 were positively correlated, whereas the amount of body fluid removed and changes in the concentration of syndecan-1 were not correlated. The reduction in amount of body fluid removed and dialysis time inhibited the change in of syndecan-1 levels before and after hemodialysis. In conclusion, quantitative assessment of the endothelial glycocalyx injury during hemodialysis can be done by measuring the concentration of serum syndecan-1 which may aid in the selection of appropriate anticoagulants, hemodialysis time, and the amount of body fluid removed.

\section{Introduction}

Malnutrition, inflammation, and atherosclerosis are strongly associated in chronic kidney disease ${ }^{1}$. and both a malnourished state and atherosclerosis can be caused by inflammation. Moreover, chronic microinflammation is observed in patients who undergo hemodialysis ${ }^{2}$. Several factors, such as uremia, activation of free radicals and adhesion molecules, and hemodialysis membrane, lead to microinflammation in patients who undergo hemodialysis ${ }^{3-5}$. Uremic substances and the hemodialysis membrane promote the production of free radicals and cytokines by stimulating neutrophils, and the resulting inflammation further causes endothelial injury. However, there is no method to quantitatively assess endothelial cells injury.

The vascular endothelium is composed of a thin monolayer of endothelial cells, and this lines the entire circulatory system, particularly those parts that are exposed to the circulating blood. The healthy endothelium is covered by a sugar-protein called glycocalyx ${ }^{6-10}$ that plays pivotal roles in vascular homeostasis ${ }^{11,12}$. The endothelial glycocalyx is degraded by several factors, such as sepsis, major surgery, trauma, ischemia/reperfusion, and prolonged hyperglycemia. Persistent and diffuse alterations in the glycocalyx are associated with widespread endothelial dysfunction, changed permeability, and impaired oxygen and nutrient delivery to the cells ${ }^{11,13,14}$. Several studies have revealed the relationship between endothelial glycocalyx injury and serious diseases, such as cardiovascular disease, acute kidney injury, and chronic kidney disease ${ }^{15,16}$. Moreover, the structure of the endothelial glycocalyx is degraded in chronic diseases, such as aging ${ }^{17}$, diabetes ${ }^{18}$, and hypertriglyceridemia ${ }^{19}$. 
The glycocalyx comprises cell-bound proteoglycans, glycosaminoglycan side chains, and sialoproteins ${ }^{13,20}$. The proteoglycans consist of a core protein, such as a member of the syndecan protein family, to which glycosaminoglycan molecules are linked ${ }^{21}$. Syndecan-1 is the core protein in heparan sulfate proteoglycan that is found in the glycocalyx. Syndecan-1 is released from the endothelium when the glycocalyx is injured, causing an increase in its concentration in circulation ${ }^{22}$. Moreover, serum syndecan-1 has been used as an endothelial injury marker in recent clinical studies in critically ill patients ${ }^{23-26}$.

Therefore, the present study aimed to assess endothelial injury using serum syndecan-1 as a marker of endothelial glycocalyx injury in patients who underwent hemodialysis. Additionally, the present study examined the medication type and factors that influence the concentration of syndecan-1.

\section{Results}

\section{Characteristics of patients}

We finally enrolled 145 patients with a median age of 66 years (Fig. 1, Table 1). The median dialysis period and dialysis time were 63 months and 3.7 hours, respectively. The most common primary illness was diabetic nephropathy which was observed in 37 patients $(25.5 \%)$. 
Table 1

Patient demographics.

\begin{tabular}{|ll|}
\hline Characteristics & Median (range) or number \\
\hline Number of cases, $\mathrm{n}$ & 145 \\
\hline Age (years), mean (IQR) & $68(60-77)$ \\
\hline Sex (female/male), $\mathrm{n}(\%)$ & $44(30.3) / 101(69.7)$ \\
\hline Dialysis period (months), median (IQR) & $20.0(1.0,87.0)$ \\
\hline Dialysis time (hours), median (IQR) & $4.0(3.0,4.0)$ \\
\hline Primary illness, $\mathrm{n}(\%)$ & \\
\hline Chronic glomerulonephritis & $29(20.0)$ \\
\hline Rapidly progressive glomerulonephritis & $4(2.8)$ \\
\hline Polycystic kidney disease & $8(5.5)$ \\
\hline Nephrosclerosis & $8(5.5)$ \\
\hline Diabetic nephropathy & $37(25.5)$ \\
\hline Nephritis with autoimmune disease & $6(4.1)$ \\
\hline Renal/urological tumor & $5(3.4)$ \\
\hline Obstructive urinary tract/urination disorders & $1(0.7)$ \\
\hline Paraproteinemia (myeloma) & $1(0.7)$ \\
\hline Acute kidney injury & $10(6.9)$ \\
\hline Congenital anomalies of the kidney and urinary tract & $1(0.7)$ \\
\hline Unknown & $33(22.8)$ \\
\hline Others & $2(1.4)$ \\
\hline Hemodialysis type, $n$ (\%) & $12(8.3)$ \\
\hline HD & \\
\hline HDF & \\
\hline Dialysis efficiency & \\
\hline Kt/V & \\
\hline Medication, $n$ (\%) & \\
\hline Unfractionated heparin & \\
\hline
\end{tabular}




\begin{tabular}{|lc|}
\hline Characteristics & Median (range) or number \\
\hline Low-molecular-weight heparin & $24(16.6)$ \\
\hline Nafamostat mesylate & $20(13.8)$ \\
\hline Dialysis membrane, $\mathrm{n}(\%)$ & $110(75.9)$ \\
\hline Polyethersulfone & $34(23.4)$ \\
\hline Polysulfone & $1(0.7)$ \\
\hline Asymmetric triacetate & \\
\hline$H D$ hemodialysis, HDF hemodiafiltration, IQR interquartile range. \\
\hline
\end{tabular}

The number of patients who underwent hemodialysis and hemodiafiltration was 133 (91.7\%) and 12 (8.3\%), respectively. Anticoagulation agents, such as unfractionated heparin, low-molecular-weight heparin, and nafamostat mesylate, were administered to 101, 24, and 20 patients, respectively. Median $\mathrm{Kt} / \mathrm{V}$, an index of dialysis efficiency, was 1.20.

\section{Concentration Of Serum Syndecan-1 And Hemodialysis}

The concentration of serum syndecan- 1 before and after hemodialysis was $124.6 \pm 107.8 \mathrm{ng} / \mathrm{mL}$ and $229.0 \pm 138.1 \mathrm{ng} / \mathrm{mL}$, respectively; this indicates that the concentration of serum syndecan- 1 had significantly increased $(P<0.001)$ after hemodialysis (Table 2$)$.

Table 2

Serum SDC-1 concentration before and after hemodialysis.

\begin{tabular}{|lll|}
\hline Status & SDC-1 concentration $(\mathrm{ng} / \mathrm{mL})$ & $P$-value \\
\hline Before HD & $124.6 \pm 107.8$ & $<0.001$ \\
\hline After HD & $229.0 \pm 138.1$ & \\
\hline SDC-1 syndecan- $1, H D$ hemodialysis. & \\
\hline \multicolumn{2}{|l}{$P$-values were obtained from a mixed-effects model. } \\
\hline
\end{tabular}

The concentration of serum syndecan-1 significantly increased after hemodialysis in patients who received unfractionated heparin and low-molecular-weight heparin; however, the concentration of syndecan-1 was not significantly different before and after hemodialysis in those who received nafamostat mesylate (Table 3). 
Table 3

Serum SDC-1 concentration and anticoagulants.

\begin{tabular}{|llll|}
\hline Anticoagulants & Before $\mathrm{HD}(\mathrm{ng} / \mathrm{mL})$ & After $\mathrm{HD}(\mathrm{ng} / \mathrm{mL})$ & $P$-value \\
\hline Unfractionated heparin & $112.0 \pm 79.8$ & $235.4 \pm 126.8^{*}$ & $<0.001$ \\
\hline Low-molecular-weight heparin & $144.1 \pm 135.8$ & $248.5 \pm 174.1^{*}$ & $<0.001$ \\
\hline Nafamostat mesylate & $164.2 \pm 171.1$ & $173.3 \pm 141.3$ & 0.459 \\
\hline SDC-1 syndecan-1, HD hemodialysis. & & \\
\hline
\end{tabular}

Additionally, according to the multivariable regression analysis after adjusting for age, sex, dry weight, and dialysis period, treatment with nafamostat mesylate inhibited the increase in the concentration of serum syndecan-1 during hemodialysis compared to treatment with unfractionated heparin and lowmolecular-weight heparin (Table 4).

Table 4

Results of multivariable regression analysis between anticoagulants.

\begin{tabular}{|lcccc|}
\hline Anticoagulants & Coefficient* & 95\% LCL & $\begin{array}{l}95 \% \\
\text { UCL }\end{array}$ & $\begin{array}{l}\boldsymbol{P} \\
\text { value }\end{array}$ \\
\hline $\begin{array}{l}\text { Low-molecular-weight heparin vs. unfractionated } \\
\text { heparin }\end{array}$ & -18.07 & -56.776 & 20.637 & 0.358 \\
\hline Nafamostat mesylate vs. unfractionated heparin & -116.473 & -158.442 & -74.504 & $<$ \\
\hline $\begin{array}{l}\text { Nafamostat mesylate vs. low-molecular-weight } \\
\text { heparin }\end{array}$ & -98.403 & -150.482 & -45.324 & $<$ \\
\hline $\begin{array}{l}\text { *Coefficients from the multivariable linear regression model adjusted for age, sex, dry weight, and } \\
\text { dialysis period, shown as differences in serum syndecan-1 concentration for low-molecular-weight }\end{array}$ \\
$\begin{array}{l}\text { heparin vs. unfractionated heparin, nafamostat mesylate vs. unfractionated heparin, and nafamostat } \\
\text { mesylate vs. low-molecular-weight heparin, respectively. }\end{array}$ \\
\hline \begin{tabular}{lllll}
\hline LCL lower confidence limit, UCL upper confidence limit. \\
\hline
\end{tabular} \\
\hline
\end{tabular}

\section{Association of concentration of serum syndecan-1 with dialysis time and body fluid removal}

The relationship between the concentration variability of syndecan- 1 and the dialysis condition, including the dialysis time and the amount of body fluid removed, was confirmed. The amount of body fluid removal was corrected by dry weight. The dialysis time and change in concentration of syndecan-1 showed positive correlation $(P=0.033)$, but there was no significant association $(P=0.111)$ between the amount of body fluid removed and changes in the concentration of syndecan-1 (Table 5). 
Table 5

Relationship between syndecan-1 concentration variability and dialysis conditions.

\begin{tabular}{lllll}
\hline Factors & Coefficient* & $\begin{array}{c}95 \% \\
\text { LCL }\end{array}$ & $\begin{array}{c}95 \% \\
\text { UCL }\end{array}$ & $\begin{array}{l}\boldsymbol{P} \\
\text { value }\end{array}$ \\
$\begin{array}{l}\text { Body fluid removed/dry weight (per 0.01 L/Kg } \\
\text { increase) }\end{array}$ & 9.107 & 0.144 & 18.07 & 0.111 \\
\hline $\begin{array}{l}\text { Dialysis time } \\
\text { (per } 1 \text { minute increase) }\end{array}$ & 23.349 & -8.836 & 55.533 & 0.033 \\
\hline $\begin{array}{l}\text { *Coefficients from the multivariable linear regression model adjusted for age, sex, and dialysis period, } \\
\text { shown as increment in serum syndecan-1 concentration for a unit change in factors. }\end{array}$ & & & \\
\hline
\end{tabular}

Next, we examined the association between changes in the concentration of syndecan-1 and dialysis parameters, including dialysis time and the amount of body fluid removed. The change in the concentration of syndecan-1 before and after hemodialysis increased with respect to enhanced removal of body fluids and prolonged dialysis time ( $P$ for interaction $=0.063$, Fig. 2$)$. However, the amount of change in the concentration of syndecan-1 before and after hemodialysis decreased with respect to a decrease in the amount of body fluid removed and shortened dialysis time.

\section{Discussion}

The present study revealed that a) the endothelial glycocalyx is injured during hemodialysis; $b$ ) endothelial glycocalyx injury is attenuated by administering nafamostat mesylate as an anticoagulant; and c) endothelial glycocalyx injury is aggravated by an increase in the amount of body fluid removed and prolonged dialysis time.

The endothelial glycocalyx is injured in patients with chronic kidney disease and by plasma volume expansion ${ }^{27}$. Therefore, we hypothesized that the serum syndecan-1 levels would increase in patients who undergo hemodialysis. A previous study indicated that the concentration of serum syndecan- 1 was approximately $20 \mathrm{ng} / \mathrm{mL}$ in healthy people ${ }^{19}$; in contrast, in the present study, it was $124.6 \pm 107.8 \mathrm{ng} / \mathrm{mL}$ in patients who underwent hemodialysis. This result confirmed that the endothelial glycocalyx sustained injuries in patients who undergo hemodialysis.

Endothelial glycocalyx injury may be attenuated by a decrease in fluid volume after hemodialysis. However, the levels of serum syndecan-1 increased after hemodialysis than those before hemodialysis. This finding suggests that the endothelial glycocalyx is injured during hemodialysis due to neutrophils and inflammation via the production of free radicals and cytokines.

During hemodialysis, unfractionated heparin, low-molecular-weight heparin, and nafamostat mesylate were used as anticoagulating agents. Low-molecular-weight heparin and nafamostat were administered 
in patients that had any disease which was associated with bleeding tendencies. The results of the present study suggest that an increase in the concentration of syndecan-1 is attenuated in patients who receive nafamostat mesylate.

Nafamostat mesylate, a synthetic serine protease inhibitor, is a short-acting anticoagulant ${ }^{28}$, and is also used during hemodialysis to prevent proteolysis of fibrinogen into fibrin ${ }^{29}$. It is a slow, tight-binding substrate that traps the target protein in the acyl-enzyme intermediate form, and inhibits enzyme activity $^{30,31}$. Nafamostat has been recently identified as a potential therapy against COVID-19 ${ }^{32}$. Infection with SARS-CoV-2 induces endotheliitis due to viral involvement and inflammatory response of the host, and thus, it is associated with endothelial glycocalyx injury ${ }^{21}$. Therefore, nafamostat mesylate may have a beneficial effect on the endothelial glycocalyx, although it is supported by only circumstantial evidence.

Extension of dialysis time is a strategy to improve prognosis ${ }^{33}$; however, it remains controversial ${ }^{33,34}$. The present study identified that changes in the levels of serum syndecan-1 are small in patients who have prolonged dialysis time and slow removal of body fluid. Therefore, these two strategies could prevent endothelial glycocalyx injury. Several reports have also revealed that prolonged hemodialysis was associated with improved blood pressure and fluid management ${ }^{35-37}$. Additionally, rapid removal of body fluid is associated with a greater risk of mortality and cardiovascular events ${ }^{38}$. Moreover, hypotension during hemodialysis is also associated with higher mortality ${ }^{39}$.

These mechanisms may explain how lower ultrafiltration rates with prolonged hemodialysis and slow removal of body fluids may ameliorate endothelial vascular permeability via attenuation of endothelial glycocalyx injury. Therefore, we propose that slow removal of body fluids with prolonged hemodialysis can reduce hypotension during hemodialysis.

This study has some limitations. First, the hemodialysis time in most patients was less than $4 \mathrm{~h}$. Therefore, an accurate examination of prolonged hemodialysis could not be performed. Second, less type of dialyzer was used in the present study. Although further studies are required, measuring the concentration of serum syndecan-1 may help in the assessment of endothelial injury under low blood flow (e.g., chronic hemodiafiltration), and of membrane compatibility by using a different type of dialyzer. Moreover, serum syndecan-1 is proposed to be a useful biomarker for daily monitoring of organ dysfunction, and may be an important risk factor for mortality in critically ill patients ${ }^{25}$.

In conclusion, the study presented a method for the quantitative assessment of endothelial glycocalyx injury by measuring the concentration of serum syndecan- 1 during hemodialysis. Although hemodialysis causes endothelial glycocalyx injury, it may be mitigated by maintenance of hemodialysis duration and by modulation of the amount of body fluid removed via the quantitative assessment of the serum syndecan-1.

\section{Methods}




\section{Patients}

This was a single-center, retrospective, observational study conducted at the Gifu University Hospital, affiliated to Gifu University, Gifu, Japan. Patients who underwent hemodialysis at the Gifu University Hospital between March 2017 and December 2019 were enrolled in the study. Patients aged <20 years, who underwent plasma apheresis, plasma exchange, and double filtration plasma therapy, and who had not maintained their dry weight were excluded from the analysis. Finally, data from 145 patients were used for the final analyses in this study (Fig. 1).

\section{Ethics approval and consent to participate}

The study conformed to the principles outlined in the Declaration of Helsinki ${ }^{40}$. Ethics approval was obtained from the Medical Ethics Committee of the Gifu University Graduate School of Medicine, Gifu, Japan (record no.: 2021-A005). The need for informed consent from participants was waived by the medical ethics committee due to the retrospective nature of the study. Before initiation, the study was registered in the UMIN Clinical Trials Registry (registry number: UMIN000051415).

\section{Data collection and study design}

Blood was routinely sampled before and after hemodialysis from eligible patients at the time of last hemodialysis before being discharged from Gifu University Hospital, and data from these blood samples were used in the present study. All laboratory data (except serum syndecan-1), dry weight, and other patient demographics were extracted from the hospital's electronic medical records. The concentration of serum syndecan-1 was measured using an enzyme-linked immunosorbent assay (950.640.192; Diaclone, Besancon, Cedex, France). The data were retrospectively analyzed. As an index of the efficiency of dialysis, Kt/V was calculated as described previously ${ }^{41}$.

\section{Statistical analysis}

Patients' baseline characteristics are presented as median and interquartile range (IQR) for continuous variables, and frequency and proportion for categorical variables. For the primary analysis, a mixed effect model was used to assess the change in syndecan- 1 levels with hemodialysis. The difference in syndecan-1 levels before and after hemodialysis in the anticoagulant subgroup was confirmed using paired $t$-test. A multivariable linear regression analysis was performed to compare the change in syndecan-1 levels before/after hemodialysis and treatment with anticoagulants. The covariates in the regression model were age, sex, dry weight, and dialysis period ${ }^{42}$. These variables were selected a priori on the basis of previous studies. In another model, dry weight and dialysis period were simultaneously incorporated into the linear regression model to evaluate the effect of factors during dialysis on the levels of syndecan-1. An interaction term was included in the model to confirm the effect of modification of dry weight and dialysis period on changes in the levels of syndecan-1. If the interaction term was statistically significant, the effect of the dialysis period (or dry weight) on syndecan-1 was determined to be modified by dry weight (or the dialysis period). There were no missing values in the data used in the analyses. A 
two-sided $P<0.05$ was considered to be statistically significant. The study is exploratory and there were concerns about low statistical power; therefore, the interaction was evaluated with a two-sided $P<0.1$. $\mathrm{R}$ version 4.1.0 was used for statistical analyses (www.r-project.org).

\section{Data availability}

The data that support the findings of this study are available from the corresponding author $(\mathrm{HO})$ upon reasonable request.

\section{Declarations}

\section{Acknowledgements}

The authors would like to thank the paramedical crew that shared the data obtained by them with us and allowed us to use the data for the writing of this report. The authors thank Editage (www.editage.com) for English language editing.

\section{Author contributions}

K.K. and H. Okada wrote the manuscript. K.K., Kodai S., S.N., H. Okamoto, G.Y., R.K., and T. Miura collected the blood samples. Y. Keiko S., C.T., Y. Kawasaki, T. Minamiyama., A.N., H.F., T.S., Y.T., Tomoki Y., and Y.N. measured the syndecan-1 concentration using ELISA. Keiko S. and R.Y. created a database. T.I. performed statistical analysis. Y.M., T. Miyake, Y. Kitagawa, T.F., T.D., and Takahiro Y. treated the patients. H.T., S.Y., and S.O. supervised the study. H. Okada and A.S. revised and edited the manuscript. The final manuscript was reviewed and approved by all authors.

\section{Competing interests}

All authors declare no competing interests.

\section{Funding}

This work was supported by the Ministry of Education, Science and Culture of Japan grants-in-aid for scientific research [grant numbers 19H03756, 19K18347, 19K09410, 18K16511].

\section{References}

1. Stenvinkel, P. et al. Strong association between malnutrition, inflammation, and atherosclerosis in chronic renal failure. Kidney Int, 55, 1899-1911 https://doi.org/10.1046/j.1523-1755.1999.00422.x (1999).

2. Zimmermann, J., Herrlinger, S., Pruy, A., Metzger, T. \& Wanner, C. Inflammation enhances cardiovascular risk and mortality in hemodialysis patients. Kidney Int, 55, 648-658 https://doi.org/10.1046/j.1523-1755.1999.00273.x (1999). 
3. Kultz, D. Hyperosmolality triggers oxidative damage in kidney cells. Proc Natl Acad Sci U S A, 101, 9177-9178 https://doi.org/10.1073/pnas.0403241101 (2004).

4. Rashid, G., Benchetrit, S., Fishman, D. \& Bernheim, J. Effect of advanced glycation end-products on gene expression and synthesis of TNF-alpha and endothelial nitric oxide synthase by endothelial cells. Kidney Int, 66, 1099-1106 https://doi.org/10.1111/j.1523-1755.2004.00860.x (2004).

5. Kawabata, K. et al. CD31 expression on leukocytes is downregulated in vivo during hemodialysis. Nephron, 89, 153-160 https://doi.org/10.1159/000046062 (2001).

6. Ando, Y. et al. Brain-Specific Ultrastructure of Capillary Endothelial Glycocalyx and Its Possible Contribution for Blood Brain Barrier. Sci Rep, 8, 17523 https://doi.org/10.1038/s41598-018-35976-2 (2018).

7. Becker, B. F., Chappell, D. \& Jacob, M. Endothelial glycocalyx and coronary vascular permeability: the fringe benefit. Basic Res Cardiol, 105, 687-701 https://doi.org/10.1007/s00395-010-0118-z (2010).

8. Inagawa, R. et al. Ultrastructural Alteration of Pulmonary Capillary Endothelial Glycocalyx During Endotoxemia., 154, 317-325 https://doi.org/10.1016/j.chest.2018.03.003 (2018).

9. Okada, H. et al. Three-dimensional ultrastructure of capillary endothelial glycocalyx under normal and experimental endotoxemic conditions. Crit Care, 21, 261 https://doi.org/10.1186/s13054-0171841-8 (2017).

10. Rehm, M. et al. Endothelial glycocalyx as an additional barrier determining extravasation of $6 \%$ hydroxyethyl starch or 5\% albumin solutions in the coronary vascular bed., 100, 1211-1223 https://doi.org/10.1097/00000542-200405000-00025 (2004).

11. Chelazzi, C., Villa, G., Mancinelli, P., De Gaudio, A. R. \& Adembri, C. Glycocalyx and sepsis-induced alterations in vascular permeability. Crit Care, 19, 26 https://doi.org/10.1186/s13054-015-0741-z (2015).

12. Woodcock, T. E. \& Woodcock, T. M. Revised Starling equation and the glycocalyx model of transvascular fluid exchange: an improved paradigm for prescribing intravenous fluid therapy. $\mathrm{Br} J$ Anaesth, 108, 384-394 https://doi.org/10.1093/bja/aer515 (2012).

13. Salmon, A. H. \& Satchell, S. C. Endothelial glycocalyx dysfunction in disease: albuminuria and increased microvascular permeability. J Pathol, 226, 562-574 https://doi.org/10.1002/path.3964 (2012).

14. Henrich, M., Gruss, M. \& Weigand, M. A. Sepsis-induced degradation of endothelial glycocalix. ScientificWorldJournal, 10, 917-923 https://doi.org/10.1100/tsw.2010.88 (2010).

15. Liborio, A. B. et al. Endothelial glycocalyx damage is associated with leptospirosis acute kidney injury. Am J Trop Med Hyg, 92, 611-616 https://doi.org/10.4269/ajtmh.14-0232 (2015).

16. Padberg, J. S. et al. Damage of the endothelial glycocalyx in chronic kidney disease. Atherosclerosis, 234, 335-343 https://doi.org/10.1016/j.atherosclerosis.2014.03.016 (2014).

17. Machin, D. R. et al. Advanced age results in a diminished endothelial glycocalyx. Am J Physiol Heart Circ Physiol, 315, H531-H539 https://doi.org/10.1152/ajpheart.00104.2018 (2018). 
18. Nieuwdorp, M. et al. Loss of endothelial glycocalyx during acute hyperglycemia coincides with endothelial dysfunction and coagulation activation in vivo., 55, 480-486 (2006).

19. Oda, K. et al. Factors Enhancing Serum Syndecan-1 Concentrations: A Large-Scale Comprehensive Medical Examination. J Clin Med, 8, https://doi.org/10.3390/jcm8091320 (2019).

20. Paulus, P., Jennewein, C. \& Zacharowski, K. Biomarkers of endothelial dysfunction: can they help us deciphering systemic inflammation and sepsis? Biomarkers 16 Suppl 1, S11-21, doi:10.3109/1354750X.2011.587893 (2011).

21. Okada, H., Yoshida, S., Hara, A., Ogura, S. \& Tomita, H. Vascular endothelial injury exacerbates coronavirus disease 2019: The role of endothelial glycocalyx protection., 28, e12654 https://doi.org/10.1111/micc.12654 (2021).

22. Rehm, M. et al. Shedding of the endothelial glycocalyx in patients undergoing major vascular surgery with global and regional ischemia., 116, 1896-1906 https://doi.org/10.1161/CIRCULATIONAHA.106.684852 (2007).

23. Ostrowski, S. R. et al. Association between biomarkers of endothelial injury and hypocoagulability in patients with severe sepsis: a prospective study. Crit Care, 19, 191 https://doi.org/10.1186/s13054015-0918-5 (2015).

24. Puskarich, M. A., Cornelius, D. C., Tharp, J., Nandi, U. \& Jones, A. E. Plasma syndecan-1 levels identify a cohort of patients with severe sepsis at high risk for intubation after large-volume intravenous fluid resuscitation. J Crit Care, 36, 125-129 https://doi.org/10.1016/j.jcrc.2016.06.027 (2016).

25. Suzuki, K. et al. Serum syndecan-1 reflects organ dysfunction in critically ill patients. Sci Rep, 11, 8864 https://doi.org/10.1038/s41598-021-88303-7 (2021).

26. Suzuki, K. et al. Possible involvement of Syndecan-1 in the state of COVID-19 related to endothelial injury. Thromb J, 19, 5 https://doi.org/10.1186/s12959-021-00258-x (2021).

27. Berg, S., Golster, M. \& Lisander, B. Albumin extravasation and tissue washout of hyaluronan after plasma volume expansion with crystalloid or hypooncotic colloid solutions. Acta Anaesthesiol Scand, 46, 166-172 https://doi.org/10.1034/j.1399-6576.2002.460207.x (2002).

28. Al-Horani, R. A. \& Desai, U. R. Recent advances on plasmin inhibitors for the treatment of fibrinolysisrelated disorders. Med Res Rev, 34, 1168-1216 https://doi.org/10.1002/med.21315 (2014).

29. Sadahiro, T. et al. Current Practices in Acute Blood Purification Therapy in Japan and Topics for Further Study. Contrib Nephrol, 196, 209-214 https://doi.org/10.1159/000485724 (2018).

30. Ramjee, M. K., Henderson, I. M., McLoughlin, S. B. \& Padova, A. The kinetic and structural characterization of the reaction of nafamostat with bovine pancreatic trypsin. Thromb Res, 98, 559569 https://doi.org/10.1016/s0049-3848(00)00206-1 (2000).

31. Ramjee, M. K. \& Patel, S. Continuous-flow injection microfluidic thrombin assays: The effect of binding kinetics on observed enzyme inhibition. Anal Biochem, 528, 38-46 https://doi.org/10.1016/j.ab.2017.04.016 (2017).

32. Wang, M. et al. Remdesivir and chloroquine effectively inhibit the recently emerged novel coronavirus (2019-nCoV) in vitro. Cell Res, 30, 269-271 https://doi.org/10.1038/s41422-020-0282-0 (2020). 
33. Chertow, G. M. et al. Long-Term Effects of Frequent In-Center Hemodialysis. J Am Soc Nephrol, 27, 1830-1836 https://doi.org/10.1681/ASN.2015040426 (2016).

34. Rocco, M. V. et al. Long-term Effects of Frequent Nocturnal Hemodialysis on Mortality: The Frequent Hemodialysis Network (FHN) Nocturnal Trial. Am J Kidney Dis, 66, 459-468 https://doi.org/10.1053/j.ajkd.2015.02.331 (2015).

35. Burton, J. O., Jefferies, H. J., Selby, N. M. \& Mclntyre, C. W. Hemodialysis-induced repetitive myocardial injury results in global and segmental reduction in systolic cardiac function. Clin J Am Soc Nephrol, 4, 1925-1931 https://doi.org/10.2215/CJN.04470709 (2009).

36. Lacson, E. Jr. et al. Survival with three-times weekly in-center nocturnal versus conventional hemodialysis. J Am Soc Nephrol, 23, 687-695 https://doi.org/10.1681/ASN.2011070674 (2012).

37. Ok, E. et al. Comparison of 4- and 8-h dialysis sessions in thrice-weekly in-centre haemodialysis: a prospective, case-controlled study. Nephrol Dial Transplant, 26, 1287-1296 https://doi.org/10.1093/ndt/gfq724 (2011).

38. Flythe, J. E., Kimmel, S. E. \& Brunelli, S. M. Rapid fluid removal during dialysis is associated with cardiovascular morbidity and mortality. Kidney Int, 79, 250-257 https://doi.org/10.1038/ki.2010.383 (2011).

39. Flythe, J. E., Xue, H., Lynch, K. E., Curhan, G. C. \& Brunelli, S. M. Association of mortality risk with various definitions of intradialytic hypotension. J Am Soc Nephrol, 26, 724-734 https://doi.org/10.1681/ASN.2014020222 (2015).

40. Rickham, P. P., Human Experimentation \& Code of Ethics of the World Medical Association. Declaration of Helsinki. Br Med J, 2, 177 https://doi.org/10.1136/bmj.2.5402.177 (1964).

41. Daugirdas, J. T. Second generation logarithmic estimates of single-pool variable volume Kt/V: an analysis of error. J Am Soc Nephrol, 4, 1205-1213 https://doi.org/10.1681/ASN.V451205 (1993).

42. Koch, J. et al. An acute rise of plasma $\mathrm{Na}(+)$ concentration associates with syndecan-1 shedding during hemodialysis. Am J Physiol Renal Physiol, 319, F171-F177 https://doi.org/10.1152/ajprenal.00005.2020 (2020).

\section{Figures}


Figure 1

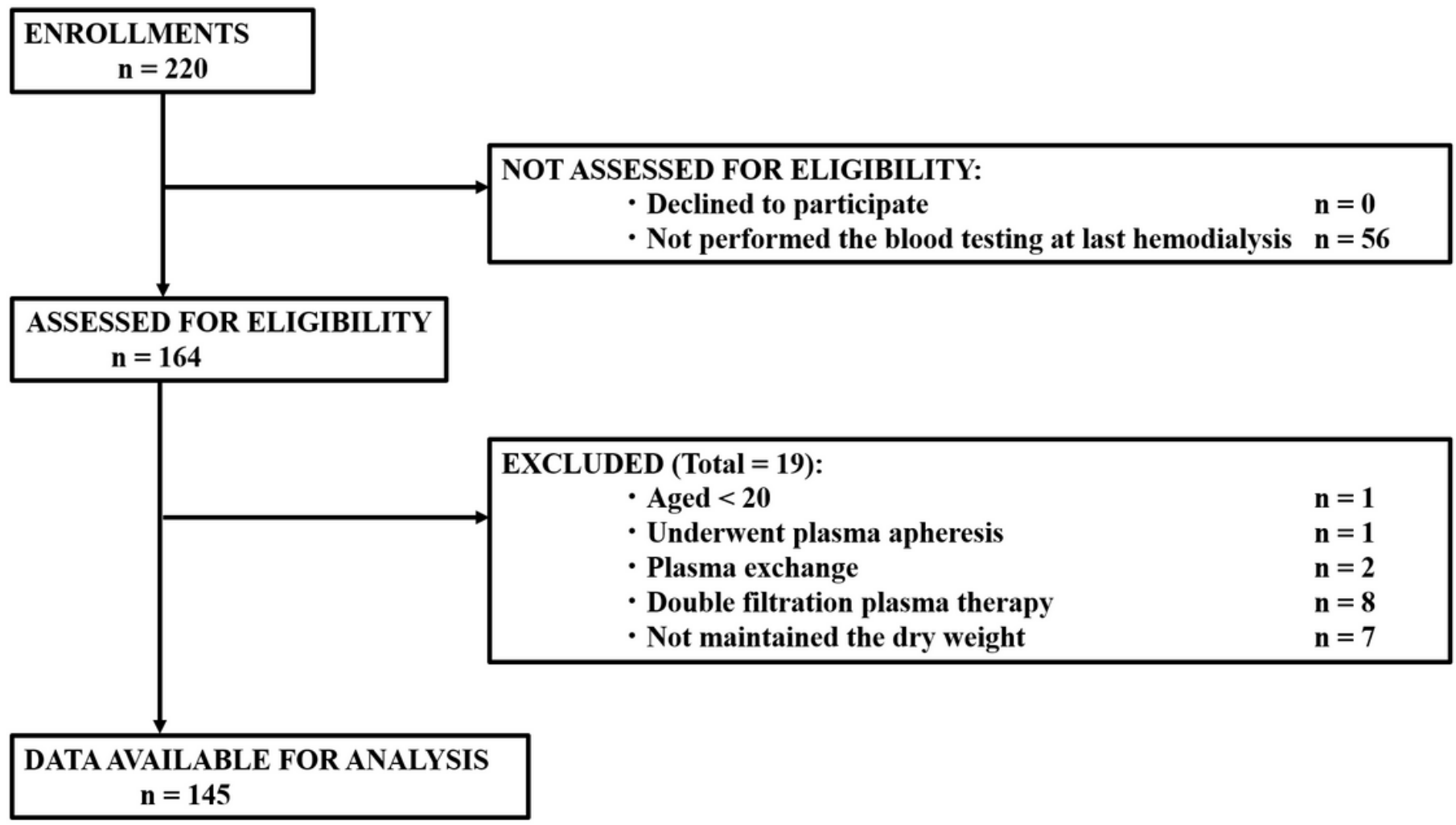

Figure 1

Flow diagram for the selection of study participants for data analysis. 


\section{Figure 2}

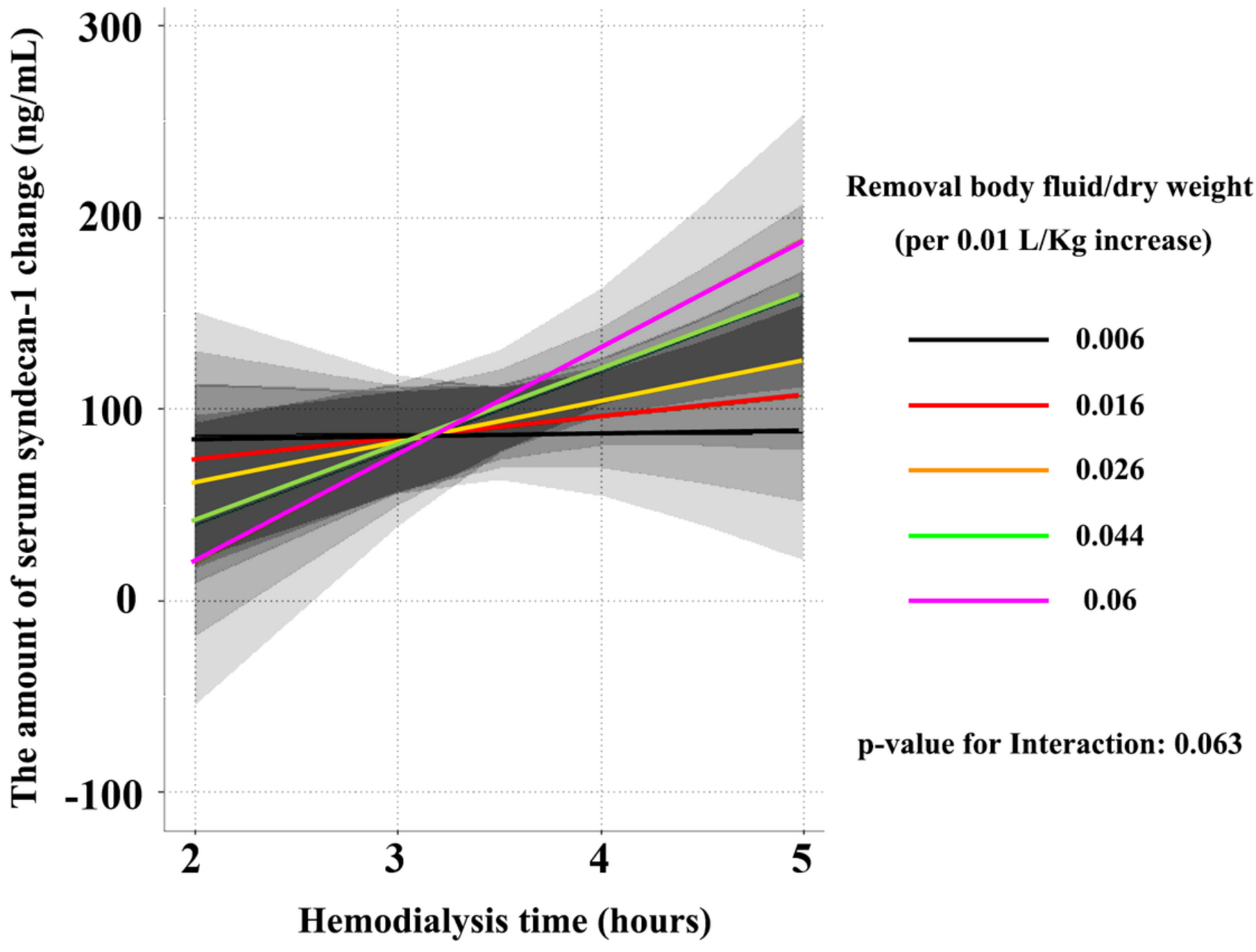

Figure 2

Effect of dialysis time and the amount of body fluid removed on the change in the serum syndecan-1 concentration. The change in the concentration of syndecan-1 before and after hemodialysis increased with respect to the enhanced body fluid removal and prolonged dialysis time. However, the change in the concentration of syndecan-1 before and after hemodialysis decreased with respect to the decreased amount of body fluid removal and the shortened dialysis time. 